\title{
El papel de representación internacional de SEDOPTICA
}

Transcurridos los primeros seis meses desde que accedí a la Presidencia de SEDOPTICA, he decidido aprovechar este editorial de nuestra revista OPA, para informar acerca de la actividad de SEDOPTICA como representante internacional de la comunidad científica española de la Óptica y la Fotónica. Estos últimos meses me han servido para conocer de primera mano y acceder directamente a esta importante labor que SEDOPTICA desempeña en la representación internacional de nuestra comunidad. A pesar de mis años de vinculación a SEDOPTICA, debo reconocer que conocía esta labor solamente de manera parcial. Es por ello, que deseo aprovechar este editorial para dar a conocer esta actividad de representación internacional y poder así informar de ella a todos nuestros socios y a otros colegas.

SEDOPTICA, como sociedad científica española cuya actividad está específicamente centrada en el campo de la Óptica y la Fotónica, es la sociedad que representa a España en tres organizaciones internacionales de este ámbito del conocimiento: en la International Comission for Optics (ICO), en la European Optica Society (EOS), y en la Red Iberoamericana de Óptica (RIAO).

La ICO (http://e-ico.org/) es la organización internacional que reúne a representantes del campo de la óptica de diferentes países, así como a representantes de las principales organizaciones y sociedades científicas relacionadas con el campo de la Óptica y la Fotónica (https://en.wikipedia.org/wiki/International Co mmission for Optics). Se organiza en Comités Territoriales. La representación territorial española corre a cargo del Presidente del Comité de Técnicas de la Imagen de SEDOPTICA. ICO ha contado con la implicación directa de socias relevantes de SEDOPTICA, como María J. Yzuel o María Luisa Calvo, que fue Presidenta en el periodo 2008-2011. Las socias de SEDOPTICA Rosario Martínez-Herrero y Susana Marcos obtuvieron el Premio ICO en 1990 y 2007 respectivamente. El principal evento de ICO es el Congress of the International Comission of Optics, que se celebra de manera trianual. La 23a edición se celebró en Santiago de Compostela en 2014, organizada por Humberto Michinel, y la 24aㅡ edición se celebró en Tokio este pasado mes de agosto. En dicho congreso se celebra la Asamblea General de ICO, donde el Comité Territorial español tiene tres votos. Tal y como se informa en el documento de Noticias de SEDOPTICA en este mismo número de OPA, en la Asamblea General en dicho congreso, nuestros socios Humberto Michinel y Sara Otero salieron elegidos en los puestos de Secretario y una de las Vicepresidencias de ICO respectivamente, para este próximo trienio 2017-20.

La EOS (http://www.myeos.org/) es la Sociedad Europea de Óptica, y esta constituida por sociedades locales nacionales de diversos países. SEDOPTICA es la sociedad que representa a España, y lo hace participando como Affiliated Society. El Presidente de SEDOPTICA participa directamente en Scientific Advisory Committee (SAC) de EOS. La participación de socios de SEDOPTICA en EOS ha sido también muy relevante. María Yzuel fue presidenta de EOS en el año 2009, y actualmente Humberto Michinel es Presidente-Electo de EOS.

La RIAO (http://www.riao.org.mx/) es la red que reúne a diferentes sociedades científicas del campo de la Óptica y la Fotónica del ámbito iberoamericano, y SEDOPTICA es la sociedad científica española implicada. El miembro del Consejo de RIAO representante de España es el Presidente del Comité de Técnicas de la Imagen de SEDOPTICA. Pedro Andrés ha sido Presidente de RIAO en el periodo 2013-16, y finalizó su mandato el pasado mes de noviembre de 2016, en la Asamblea General de RIAO realizada en la IX Reunión Iberoamericana de Óptica y XII Reunión Iberoamericana de Óptica, Láseres y Aplicaciones (RIAO/OPTILAS), en Pucón (Chile). Dicho 
congreso contó con una importante participación de socios de SEDOPTICA. La próxima edición está prevista en Cancún (México), en 2019.

Además, el Comité de Color de SEDOPTICA es el Regular Member que representa a España en la AIC, la International Colour Association (https://www.aic-color.org/) de la que Javier Romero ha sido Presidente en los años 2014-15.

Por último, SEDOPTICA mantiene relaciones y tiene acuerdos formales de colaboración con las dos grandes sociedades científicas de ámbito internacional: The Optical Socity (OSA) y The Society for Optics and Photonics (SPIE). También tiene acuerdos formales de colaboración con la Academia Mexicana de Óptica (AMO), con las Sociedade Portuguesa para a Investigação em Óptica e Fotónica (SPOF) y con las Société Tunisienne d'Optique (STO).

SEDOPTICA somos una sociedad científica pequeña, en comparación con otras sociedades científicas españolas que representan comunidades más numerosas. También somos pequeños en comparación con las sociedades científicas internacionales más importantes en nuestro campo, como OSA y SPIE. No obstante, la representación internacional de SEDOPTICA refleja la intensa actividad de sus socios. Es por ello que os animo a sacar el máximo provecho de esta participación en estas organizaciones internacionales y de sus iniciativas. Desde SEDOPTICA trataremos a anunciar debidamente todas sus actividades y promocionar que nuestros socios puedan aprovechar y participar en ellas.

\section{Ignacio Moreno}

Presidente Soc. Española de Óptica

Elche, Septiembre 2017

DOI: $\underline{\text { http://dx.doi.org/10.7149/OPA.50.3.i }}$ 